DOI:10.4025/5cih.pphuem.1807

\title{
Breve Reflexão Sobre o Caráter Histórico Das Biografias Plutarquianas
}

Camila Santiago Luz

Resumo: A relação entre as narrativas própria à História e a narrativa inerente à biografia desde muito antes de nossa era tem se mostrado bastante conflituosa; este fato , todavia, não nos causa espanto, ambos os gêneros parecem à nós - historiadores do século XXI - muito semelhantes, e por vezes, até mesmo complementares. É senso comum que tanto a narrativa histórica quanto a narrativa biográfica surgiram na Grécia antiga simultaneamente , contudo, para os antigos gregos e mais tarde os antigos romanos, História e biografia - do grego bio que significa vida, graphein que possui o significado de escrever, acrescido do sufixo ia responsável por marcar substantivos abstratos - eram dois gêneros narrativos singulares e distintos cuja as diferenças deveriam ser bem demarcadas e salientadas. Ora, para os pensadores greco-romanos a História , enquanto forma de conhecimento, deveria ocupar-se em descrever e perpetuar os grandes feitos políticos e militares, enquanto que a biografia era entendida em um sentido pedagógico, seu trabalho deveria ser o de fornecer exemplos e por meio deles provocar uma reflexão em seus leitores a respeito de suas próprias condutas de vida , em especial no campo da moral .De acordo com os antigos ilustrados a principal diferença entre História e biografia , afora o caráter, era o procedimento utilizado para a construção de suas narrativas. O historiador antigo, assim como , os historiadores do nosso tempo presente, preocupavam-se com a veracidade dos seus relatos fazendo uso de um método próprio, enquanto que aos biógrafos essa busca pela verdade não era exigida, a biografia era , por assim dizer, entendida como sendo muito mais próxima ao gênero literário do que ao gênero histórico . No entanto, ao analisarmos o modo utilizado para a elaboração da escrita das biografias de plutarquianas é possível distinguirmos claramente a adoção de métodos inerentes ao campo da narrativa histórica ,e mais, podemos notar nitidamente a preocupação de seu autor pela veracidade e autenticidade dos fatos por ele relatado.Neste sentido, apesar de ter escrito uma obra (Vidas Paralelas ) cuja a narrativa pertencia ao gênero biográfico e o seu autor a entende-la como tal, percebe-se que sua obra pode ser compreendida como uma obra repleta de valores históricos, em outras palavras as biografias de Plutarco de Queronéia possuem um valor histórico justamente porque - como anteriormente mencionado - foi elaborada e escrita de forma análoga a diversas obras históricas de seu tempo ,e logo, como tal, passível de ser analisada como uma narrativa histórica pelos historiadores que se dedicam a estudar a Antiguidade.

Palavras-chave: Plutarco , Biografia , História , Vidas Paralelas, Antiguidade. 
A discussão sobre se o gênero biográfico pode ou não ser considerado uma forma válida de história, há muito tempo esta presente dentro da área de atuação do historiador e se hoje as biografias mais recentes podem ser tomadas pelos pesquisadores da história sem maiores problemas, como uma fonte, cujo caráter histórico também lhe é inerente, devido a preocupação com a metodologia utilizada para se escrevê-las ,tais como, o confronto de entrevistas com documentos e registros escritos, o que podemos dizer, ou melhor como podemos enquanto historiadores da antiguidade,agir em relação as fontes biográficas de gregos e romanos antigos?

Para respondermos essa pergunta faz-se mister, primeiro compreendermos o que esses homens entendiam por História e por biografia; Vavy Pacheco Borges (2006) a respeito desse assunto salienta que a biografia, assim como, a História em quanto forma de conhecimento surgiram no mundo grego antigo simultaneamente, contudo, à biografia foi atribuído um caráter pedagógico- de dar exemplos morais negativos ou positivos- ou propagandísticos- no caso dos chamados panegíricos ou discursos de louvor,enquanto que à história ficou reservado a descrição ou perpetuação dos grandes feitos políticos e militares que eram extraídos por meio de uma pesquisa, e desta forma entendidos como verdadeiros.

De modo geral, o historiador grego estava sempre atento ao perigo de afirmar algo que não fosse verdadeiro ou sequer provável.Não que sempre tentasse evitar este perigo, mas a escolha entre o que era verdadeiro e o que não era - ou pelo menos entre o que era provável e o que não era - era, para os gregos, uma condição inerente ao trabalho do historiador.(MOMIGLIANO, 2004)

Desta feita, a adoção de uma espécie de método de questionamento e enfrentamento das fontes, buscando-se atestar a verdade ou pelo menos uma probabilidade coerente dos fatos, somados ao a concepção de que a história, enquanto espaço que contem um caráter imortalizador, deveria ocupar-se dos grandes feitos e eventos políticos e militares dos grandes homens - em sua maioria chefes de Estado - e das grandes civilizações contribuiu para que o gênero biográfico fosse relegado ao segundo plano.

A dificuldade de se enxergar as biografias - relatos de vidas - como parte integrante da história era justamente a falta dessa metodologia de pesquisa que procurava separar o verdadeiro do inventado, o plausível do não plausível e essa aleatoriedade nas escolhas das fontes sobre as quais os biógrafos construiriam a sua narrativa resultou no entendimento do gênero biográfico como sendo mais próximo a literatura do que a História.

Afora, a aleatoriedade da escolhas dos escritos os quais os biógrafos antigos usavam como base para a escrita de seus relatos de vida, o enfoque ,não `a dedicação aos grande eventos políticos e militares ,mas, pelo contrário, aos aspectos relacionados ao caráter da personagem biografada - seus vícios e virtudes - outro fator colaborou para essa diferenciação entre História e biografia no mundo antigo - compreendido aqui como o mundo greco-romano-, não cabia à História tecer "elogios,exaltações ou qualquer outro tipo de manifestação a um individuo particular"(Ziegler,Vanessa, 2009), uma vez que visava, como outrora mencionamos, relatar os fatos de forma mais próxima ao realmente ocorrido possível, porém à biografia era permitido o uso do juízo de valores exaltando ou até mesmo denegrindo ora uma personagem ora outra, isto porque seu olhar era mais voltado para as evidências de faltas e virtudes dentro do âmbito moral de seus biografados.

A crença de que a biografia era um gênero literário a - histórico tendo como argumento o fato de que não se ocupava em narrar o contexto social no qual o individuo estava envolvido, bem como, as grandes batalhas e feitos políticos militares, dando prioridade ao aspecto moralizante de sua escrita fez com que sua função fosse compreendida como a de um exempla, em outras palavras, as biografias foram entendidas como obras , cujo o seu conteúdo tinha como função fornecer exemplos de boas e más condutas e suas possíveis conseqüências. 
No entanto, o fato de que as biografias se concentravam na natureza do comportamento de seus protagonistas ao invés de ocupar-se somente com a descrição das grandes batalhas e feitos políticos não desacredita por si só o caráter histórico das obras desse gênero.

De acordo com Bruno Gentili e Giovanni Cerri (1988) em sua obra History and Biography in Ancient Thought, o que distingue a biografia da História é " a seleção das fontes biográficas, no primeiro caso majoritariamente orientada para a reconstrução do desenvolvimento educacional, no segundo para a causa de eventos políticos e militares".

Também nesse sentido Maria Aparecida de Oliveira (2006) sublinha que ao lermos a obra hercúlea de Plutarco, Vidas Paralelas "Plutarco não registrou somente a História do Individuo em suas biografias, havia em seu entorno uma sociedade que não foi ignorada por ele".

Neste sentido,percebemos então que a diferenciação entre os gêneros históricos e biográficos encontravam-se mais em uma questão de enfoque do que em sua forma de escrita.

ainda de acordo com Silva(2006), Plutarco apesar de salientar a diferença entre as narrativas históricas e biográficas " não escreveu apenas biografias mas um tipo de História", uma vez que :

Com a leitura de todas as biografias, entende-se a metodologia utilizada por Plutarco em suas narrativas e nota-se que, embora a estrutura geral corresponda à do gênero biográfico, em seu conteúdo encontramos o trabalho de investigação e reflexão que são peculiares ao historiador.(SILVA,2006)

Desta feita,observa-se que a obra gigantesca de Plutarco não pode ser desconsiderada como uma obra de cunho histórico, uma vez que, como nos lembra Silva (2006) o autor preocupavase com a verdade por de traz dos fatos por ele narrados e procurava por meio da adoção de uma metodologia utilizada por historiadores contemporâneos a ele - questionamento e comparação das fontes e da crítica ao material recolhido- construir a sua narrativa.

Plutarco nasceu em Queronéia na região grega da Beócia no ano de 46 da era atual, quando Roma já não era mais uma república e sim um império.O escritor grego pertencia a camada nobre de sua sociedade;quando completou vinte anos viajou para Atenas com intuito de ali realizar estudos de Retórica, Física, Medicina, Literatura grega e latina e Filosofia nesta ultima teve como professor o filosofo e general hoplita Ammonius responsável por despertar no então jovem escritor grego o amor pelos ensinamentos platônicos.

Após completar sua formação Plutarco viajou por diversas regiões do império romano das aquis figuram as regiões da Sícilia, Ásia menor e Alexandria.

No ano de 68d.C retornou a sua cidade natal (Queronéia) e contraiu matrimonio com Timossena (que foi sua única esposa) com ela teve 5 filhos dos quais três morreram ainda quando novos,é também em Queronéia que Plutarco começou a escrever suas obras e adentrou a carreira política ao assumir cargos públicos.

O escritor beócio viajou por diversas vezes à capital do império e lá entrou em contato com pessoas dos segmentos mais altos da sociedade romana,ganhando notoriedade e desse modo angariou o status de cidadão romano.

Durante o período de governo do Imperador Domiciano o escritor grego agora com status de cidadão romano exerceu cargos políticos e militares importantes,sendo nomeado procurador da província da Acaia,embaixador chegando até mesmo ao cargo de procônsul durante o principado de Trajano.

Afora as atividades políticas Plutarco foi sacerdote laico do famoso templo de Apolo em Delfos por mais de vinte anos e como tal organizou os jogos píticos em honra ao Deus.

Entre os anos de 119 e 125 d.C o autor de Queronéia faleceu ,mas não sem antes nos legar inúmeras obras dentre elas diversos tratados morais,políticos e religiosos, afora os pares de biografias dos homens ilustres da historia grega e romana. 
Organizados sob o nome de Moralia (obras morais e de costumes) encontra-se cerca de 78 tratados sobre ética, política, filosofia e ciência, teologia, zoologia, pedagogia e história.

Sua mais afamada obra Vidas Paralelas, constitui uma série de biografias de personalidades da historia grega e romana,elaboradas em forma de pares com a finalidade de estabelecer uma comparação entre as virtudes e defeitos comuns do par exposto,as biografias que chegaram até nós contendo 23 pares sendo que cada par compreende a vida de uma personalidade grega e uma romana, afora quatro vidas desparejadas.

Além dos relatos das vidas propriamente ditas Plutarco estabelece ao fim de quase todos os pares uma comparação entre ambos, nesta comparação o escritor beócio preocupou-se em confrontar e equipara feitos, vícios e virtudes dos pares eleitos.

Como mencionamos anteriormente ,Plutarco tinha uma grande preocupação com as fontes sobre as quais ele escreveria a suas biografias Silva (2006) ressalta que em diversas passagens ao longo da narrativa das vidas por ele descritas -em sua obra Vidas Paralelas- é possível observar essa preocupação.

Plutarco evitava registrar inadvertidamente os relatos de suas fontes, questionando-as, construindo sua narrativa a partir de comparação e da crítica do material recolhido.

Estabelecida a intenção de registrar a verdade dos fatos, era necessário recolher informações das mais variadas formas.Sobre o trabalho com as fontes, Plutarco pensava que a escrita de um texto sobre o passado requeria daquele que o elaborava um amplo conhecimento das informações legadas por seu antecessores . Como vimos na vida de Demóstenes, ele aconselhou aos interessados,inclinados a compor uma obra histórica rica em detalhes, a residir em uma cidade grande durante a pesquisa.O motivo estaria nas facilidades de contato com registros textuais e materiais variados,assim como com os relatos orais,(SILVA,2006)

Apesar da obra Vidas Paralelas consistir-se em uma narrativa biográfica que como antanhamente observamos tinha como função primeira, educar os seus leitores por meio dos relatos de vidas de personagens históricas ilustres ao descrever suas condutas morais ,políticas e cívicas e assim, obtendo como conseqüência a reflexão de cada leitor sobre o seu próprio modo de agir dentro da sociedade romana ,seu autor dedicou-se ardorosamente na verificação dos fatos e acontecimentos nela contidos chegando inclusive a realizar uma minuciosa pesquisa sobre a cronologia dos fatos.

Silva em seu livro Plutarco Historiador nos mostra que o escritor da cidade de Queronéia fez muito mais que escrever biografias voltadas somente para o lado pedagógico da narrativa ao dedicar-se com ardor pela a verdade por trás dos eventos relatados ele escreveu uma obra de cunho histórico, e que embora esse aspecto historicisante tenha passado, por vezes, despercebidos pelos historiadores da antiguidade, ele ainda continua presente e se torna mais e mais saliente quando nos deparamos com a obra inteira de Plutarco e buscamos fazer uma analise da obra como um todo ,ao invés, de privilegiarmos somente uma biografia ou um determinado conjunto de pares biográficos, e menciona que segundo o autor da região da Beócia :

O historiador deveria apoiar-se em autor reconhecido pela sociedade por seu trabalho, ter em conta a multiplicidade de relatos sobre o mesmo acontecimento,bem como ponderar sobre os costumes de seu personagem e a situação descrita pelas fontes.Com tal procedimento,Plutarco expõe seu critério de seleção das informações, o qual se pautava na estatística dos registros, na conformidade do autor e na forma cultural do agente histórico. (SILVA,2006)

Nota-se deste modo que para Plutarco fazia-se mister - ao elaborar os seus escritos biográficos - procurar apoiar-se em relatos escritos ou orais de pessoas confiáveis e de preferência renomadas pela veracidade dos seus relatos, assim como, não recorrer a somente 
uma fonte para um determinado evento histórico, mas sim ao maior numero de fontes idôneas o possível, entretanto apesar de escolher relatos confiáveis de historiadores bem conceituados da antiguidade o escritor beócio não descartava em hipótese alguma uma reflexão crítica sobre esses relatos e seus personagens.

Ora, se , como mencionamos outrora, o trabalho do historiador era para os antigos gregos, bem como, para os antigos romanas, procurar relatar por meio de seus escritos eventos políticos e militares considerados importantes para a perpetuação da civilização grega e mais tarde romana atentando-se para a veracidade dos fatos relatados, por meio da comparação de diversos testemunhos sobre um determinado evento e do mesmo modo fazer do uso questionamento crítico sobre essas fontes e seus autores, podemos nitidamente,perceber que Plutarco ao escrever suas vidas utilizou os mesmos métodos de investigação adotados pelo os responsáveis pela escrita da História.

Alem disso, o escritor da Queróneia buscou ao escrever suas biografias não realizar de forma alguma um discurso que fosse laudatório ou depreciativo à suas personagens, lembramos que isenção de um discurso de encomium, ou seja, a não elaboração de um panegírico era mais que um dever, fazia parte do caráter da escrita histórica como bem nos recordam Gentili e Cerri ao expressar o conceito de História de Políbio.

Políbio afirma que os relatos dos historiadores de Felipe da Macedônia não possuem características de uma "História", mas sim de um "encomium".Dentro do seu ponto de vista não se devia nem insultar com mentiras nem tão pouco bajular os monarcas, mas construir uma narrativa apropriada para a ilustração dos princípios e das escolhas que inspiraram suas ações ${ }^{1}$. (GENTILI;CERRI,1988)

E mais adiante ilustram o ponto de vista de Políbio ao mencionarem suas críticas em relação a Teopompus um dos ilustres biógrafos que escreveram uma biografia de Felipe da Macedônia.

Aqui começa a polemica contra Teopompus, quem, embora tendo reconhecidos grandes méritos e o gênio de Felipe da Macedônia em sua Histórias, insistiu ácida e violentamente na sua intemperança e vícios usando informações falsas.Políbio insiste em ambas passagens na idéia de que o trabalho do historiador é avaliar objetivamente os vícios e virtudes que provocaram e determinaram a ação política, rejeitando ambas as narrativas de tipo encomiásticos , mais pertinente ao relato estritamente biográficos e a narrativas tendenciosas e denegritórias. Méritos e deméritos devem ser avaliados levando em conta o quanto eles são uteis para explicar as causas do evento ${ }^{2}$. (GENTILI;CERRI,1988)

Ao observarmos a narrativa de Plutarco, notamos que suas preocupações no que concerne o seu modo de escrita, em outras palavras em como ele alicerça sua narrativa ao utilizar métodos, tais como , o confronto das fontes , a crítica sobre os relatos por ele coletados, a preocupação com a veracidade dos fatos a serem relatados, a consulta a diversas versões do mesmo evento e o cuidado em não elaborar uma narrativa de tipo laudatório ou ofensivo em muito se assemelha ao conceito de Políbio de como se deve escrever a história.

Todavia se o método adotado por Plutarco para escrever suas biografias de personagens ilustres tanto da História grega quanto da História romana se aproxima ao método defendido por Políbio como o método correto a ser utilizado ao se escrever uma obra de caráter histórico, o autor beócio prioriza de acordo com Gentili e Cerri (1988) eventos que foram ignorados por diversos escritores, porém são atestados por decretos e documentos epigrafo , sendo assim, o seu objetivo não era deforma alguma escrever uma narrativa considerada por seus contemporâneos histórica, que como vimos era baseada inteiramente em eventos políticos e militares, mas sim ,oferecer aos leitores de suas Vidas material necessário para o bom entendimento da natureza do comportamento de seus biografados.

sublinhamos, então, que embora Plutarco tenha utilizado das ferramentas próprias dos historiadores de seu tempo para construir as suas narrativas biográficas ele mesmo possuía o 
entendimento da diferença entre os gêneros biográfico e histórico, tal como os antigos a apregoavam.

Porém ,o fato de que sua forma narrativa, bem como o seu enfoque não corresponderem com a concepção de História corrente na antiguidade greco-romana não desacredita de forma alguma o aspecto histórico que pode ser claramente observado em sua obra.

Aristóteles nos adverte:

Se a obra de Heródoto houvesse sido composta em verso, nem por isso deixaria de ser obra de História, figurando ou não o metro nela.Diferem entre si porque um escreveu o que aconteceu e o outro o que poderia ter acontecido ${ }^{3}$ (Poética I45I6)

Ora, se Plutarco afirmava ter escrito biografias e não História era porque sua concepção de história era aquela de que a História só se ocupava com grandes eventos políticos e militares e não com os aspectos psicológicos daqueles que neles exerceram grande importância.

Entretanto ao adotar o procedimento próprio da escrita da História, o biografo beócio legou aos historiadores de te4mpos posteriores uma rica fonte histórica, tendo em vista que, em suas biografias apresentam-se o contexto de suas personagens que como bem argumenta Silva (2006) que sem agirem isoladamente, interagem com os demais conforme os contextos e os acontecimentos sociais.

Muito embora as discussões sobre o conceito de história estejam longe de terem um fim , uma coisa é certa, a preocupação com o contexto social será sempre um atributo dos mais importantes da narrativa própria à História , sendo assim , ao observarmos essa preocupação com o contexto social dentro das biografias plutarquianas concluímos que mais do que relatos de vidas Plutarco escreveu biografias cujo o caráter histórico é indelével e portanto não só podem como devem ser entendidas de tal forma.

\section{Referencias Bibliográficas:}

ARISTOTELES. Poética. Trad.Valentim Garcia Yebra. Madrid: Editorial Gredos,1974.

BORGES,Vavy Pacheco. Grandezas e Misérias da Biografia. In:PINSKY,Carla Bassanezi (org). Fontes Históricas. 2 ed São Paulo:Contexto,2006

CANDIDO, Antonio. Literatura e Sociedade. 7 ed. São Paulo: Nacional , 1985.

CORASSIN, Maria Luiza. Sociedade e Política na Roma Antiga. São Paulo: Editora Atual, 2001.

FINLEY, Moses I. Aspectos da Antiguidade. Lisboa, Edições 70, 1990.

FUNARI, Pedro Paulo A. Antiguidade Clássica. A história e a cultura a partir dos documentos. Campinas: Unicamp, 1995.

GENTILI,Bruno; CERRI,Giovanni. History na Biography in Ancient Thought. Amsterdam: J.C.GIEBEN, 1988

GRIMAL, Pierre. A Civilização romana. Lisboa: Edições 70, 1988.

GRIMAL, Pierre. A vida em Roma na antiguidade. Lisboa: Europa-América, 1981.

GRIMAL, Pierre. O Império Romano. Lisboa: Edições 70, 1999. 
HARVEY, Paul. Dicionário Oxford de literatura clássica. Grega e romana. Rio de Janeiro: Jorge Zahar, 1998.

MOMIGLIANO, Arnaldo. As raízes clássicas da historiografia moderna. Bauru/SP: EDUSC, 2004.

SILVA.Maria Aparecida de Oliveira. Plutarco Historiador: Análise da Biografias Espartanas. São Paulo:EDUSP,2006

SILVA.Maria Aparecida de Oliveira. Plutarco e Roma: O Mundo Grego no Império.2007.f.231.Tese (Doutorado em Historia Social)- Faculdade de Filosofia,Letras e Ciências Humanas .Universidade de São Paulo,São Paulo.

ZIEGLER.Vanessa. Plutarco e a Formação Do Governante Ideal No Principado Romano: Uma Análise Da Biografia De Alexandre.2009.f.150.Tese (Mestrado em História e Sociedade)Faculdade de Ciências e Letras .Universidade Estadual Paulista,Assis.

\section{Notas}

1- Tradução nossa

2- Tradução nossa

3- Tradução nossa 